\title{
Tolerância ao dano pelo frio e qualidade pós-colheita em goiabas 'Pedro Sato' submetidas ao condicionamento térmico
}

\author{
Cristiano André Steffens* \\ Cassandro Vidal Talamini do Amarante \\ João Paulo Generoso da Silveira \\ Ricardo Chechi \\ Bruno Pansera Espindola \\ Universidade do Estado de Santa Catarina, CAV, Departamento de Agronomia \\ Av. Luis de Camões, 2090, CEP 88520-000, Lages - SC, Brasil \\ * Autor para correspondência \\ steffens@cav.udesc.br
}

Submetido em 12/10/2007

Aceito para publicação em 10/06/2008

\section{Resumo}

O objetivo deste trabalho foi de avaliar o efeito do condicionamento térmico na tolerância ao frio e na qualidade de goiabas 'Pedro Sato' armazenadas a $2^{\circ} \mathrm{C}$. Os tratamentos avaliados foram: 30 dias a $10^{\circ} \mathrm{C}($ controle); 30 dias a $2^{\circ} \mathrm{C}$; um dia a $45^{\circ} \mathrm{C}+29$ dias a $2^{\circ} \mathrm{C}$; dois dias a $45^{\circ} \mathrm{C}+28$ dias a $2^{\circ} \mathrm{C}$; e dois dias a $35^{\circ} \mathrm{C}+28$ dias a $2^{\circ} \mathrm{C}$. Após 30 dias de armazenamento mais três dias de exposição dos frutos a $20^{\circ} \mathrm{C}$, a firmeza de polpa e a acidez titulável foram maiores nos tratamentos com condicionamento térmico. A incidência de podridões foi maior nos frutos armazenados durante 30 dias a $10^{\circ} \mathrm{C}$ e naqueles colocados por dois dias a $35^{\circ} \mathrm{C}+28$ dias a $2^{\circ} \mathrm{C}$. A perda de massa fresca foi maior nos frutos expostos durante dois dias a $45^{\circ} \mathrm{C}+28$ dias a $2^{\circ} \mathrm{C}$. Frutos armazenados por 30 dias a $2^{\circ} \mathrm{C}$ e aqueles expostos a $45^{\circ} \mathrm{C}$, antes do armazenamento a $2^{\circ} \mathrm{C}$, não apresentaram alterações substanciais na cor da epiderme durante o armazenamento e no período de exposição dos frutos a $20^{\circ} \mathrm{C}$, caracterizando o dano pelo frio.

Unitermos: Psidium guajava L., desordem fisiológica, amadurecimento, qualidade pós-colheita

\section{Abstract}

Tolerance to chilling and postharvest quality of 'Pedro Sato' guavas submitted to thermal conditioning. The objective of this work was to evaluate the effect of thermal conditioning on the chilling tolerance and quality of 'Pedro Sato' guavas stored at $2^{\circ} \mathrm{C}$. The treatments evaluated were: 30 days at $10^{\circ} \mathrm{C}$ (control); 30 days at $2^{\circ} \mathrm{C}$; one day at $45^{\circ} \mathrm{C}+29$ days at $2^{\circ} \mathrm{C}$; two days at $45^{\circ} \mathrm{C}+28$ days at $2^{\circ} \mathrm{C}$; two days at $35^{\circ} \mathrm{C}+28$ days at $2^{\circ} \mathrm{C}$. After 30 days of storage plus three days at $20^{\circ} \mathrm{C}$, the firmness of the flesh and the titratable acidity were highest in the treatments with thermal conditioning. The incidence of rot was higher in fruits stored for 30 days at $10^{\circ} \mathrm{C}$ and those kept for two days at $35^{\circ} \mathrm{C}$, and weight loss was higher in fruits kept for two days at $45^{\circ} \mathrm{C}$. Fruits stored for 30 days at $2^{\circ} \mathrm{C}$ and those kept at $45^{\circ} \mathrm{C}$, before storage at $2^{\circ} \mathrm{C}$, did not show substantial alterations in the color of the peel during storage or shelf life, which can be associated with chilling injury.

Key words: Psidium guajava L., physiological disorder, chilling injury, ripening, postharvest quality 


\section{Introdução}

A goiaba é um fruto tropical que apresenta rápido amadurecimento, o que a torna um produto muito perecível (Bron et al., 2005). O uso da refrigeração é uma técnica de armazenamento altamente eficiente para retardar o processo de amadurecimento e manter a qualidade pós-colheita dos frutos (Chitarra e Chitarra, 2005).

Em alguns frutos de clima temperado foi observado que a redução da temperatura possui maior efeito sobre a redução da atividade respiratória do que o uso da atmosfera modificada ou controlada (Steffens et al., 2007). Em goiabas, foi verificado que a redução da temperatura de $21^{\circ} \mathrm{C}$ para $11^{\circ} \mathrm{C}$ e de $11^{\circ} \mathrm{C}$ para $1{ }^{\circ} \mathrm{C}$ diminui a atividade respiratória em aproximadamente seis e três vezes, respectivamente (Bron et al., 2005). No entanto, temperaturas inadequadas, durante o armazenamento e comercialização, podem acelerar a perda da qualidade dos frutos.

Frutos tropicais são sensíveis a baixas temperaturas, desenvolvendo, nestas condições, desordens fisiológicas que podem comprometer completamente a qualidade dos mesmos. Estas desordens fisiológicas compreendem depressões na epiderme, descoloração, degenerescência interna, perda de sabor, de aroma e da capacidade de amadurecer (Hardenburg et al., 1986), sendo que a ocorrência destas desordens fisiológicas é variável com a espécie (Wang, 1994).

A temperatura ideal para o armazenamento de goiabas é em torno de $10^{\circ} \mathrm{C}$ (Durigan, 1997; Bron et al., 2005). Abaixo desta temperatura os frutos não amadurecem satisfatoriamente, caracterizando o dano pelo frio (Osman e Ayub, 1998). Em goiabas 'Kumagai', a temperatura ideal de armazenamento situa-se entre $10^{\circ} \mathrm{C}$ e $12^{\circ} \mathrm{C}$ (Jacomino et al., 2000). No entanto, estas temperaturas permitem um curto período de armazenamento, pois não ocorre uma grande redução no metabolismo dos frutos. Atualmente, algumas técnicas estão sendo utilizadas com a finalidade de aumentar a tolerância do produto ao frio (Kluge et al., 2006). O uso do condicionamento dos frutos em temperaturas elevadas, antes da refrigeração, tem permitido o armazenamento de produtos sensíveis ao dano pelo frio, em temperaturas entre $0^{\circ} \mathrm{C}$ e $2^{\circ} \mathrm{C}$, como citros (Kluge et al., 2006), tomate (Sabehat et al., 1998) e abacates (Woolf et al., 2004), sem o desenvolvimento de distúrbios fisiológicos.

O objetivo deste trabalho foi de avaliar o efeito do tratamento térmico na tolerância ao frio e na qualidade de goiabas 'Pedro Sato' armazenadas a $2^{\circ} \mathrm{C}$.

\section{Material e Métodos}

O experimento foi conduzido no ano de 2006 com goiabas, cultivar Pedro Sato, provenientes de um pomar comercial do município de Vista Alegre do Alto, SP. Os frutos foram adquiridos em uma loja varejista do município de Lages, SC, onde eram mantidos armazenados a $10^{\circ} \mathrm{C}$, desde dois dias após a colheita. O período compreendido entre a colheita e o início do experimento foi de cinco dias. Os frutos foram levados até o Laboratório de Pesquisa em Pós-Colheita da Universidade do Estado de Santa Catarina, em Lages, SC. No laboratório, foram descartados os frutos machucados e, posteriormente, realizada a homogeneização dos frutos e a separação das amostras.

$\mathrm{O}$ delineamento experimental foi o inteiramente casualizado, sendo utilizadas três repetições por tratamento. A unidade experimental foi constituída por 10 frutos. Os tratamentos utilizados foram: 30 dias a $10^{\circ} \mathrm{C}$ (controle); 30 dias a $2^{\circ} \mathrm{C}$; um dia a $45^{\circ} \mathrm{C}+29$ dias a $2^{\circ} \mathrm{C}$; dois dias a $45^{\circ} \mathrm{C}+28$ dias a $2^{\circ} \mathrm{C}$; e dois dias a $35^{\circ} \mathrm{C}+28$ dias a $2^{\circ} \mathrm{C}$. Em todos os tratamentos a umidade relativa foi de $95 \%$. Os frutos foram armazenados em câmaras tipo B.O.D. equipadas com termostato e umidostato eletrônicos.

As variáveis avaliadas foram perda de massa fresca, cor da epiderme, firmeza de polpa, acidez titulável, sólidos solúveis totais, taxas respiratória e de produção de etileno e ocorrência de podridões.

A perda de massa fresca (\%) foi avaliada durante os quatro primeiros dias de armazenamento, considerando a diferença entre massa de frutos inicial e a massa de frutos em cada dia de avaliação.

A cor da epiderme foi avaliada em termos de valores de ângulo 'hue' $\left(h^{O}\right)$, nos três primeiros dias de armazenamento, no trigésimo dia de armazenamento 
e nos três dias após remoção do armazenamento refrigerado, quando os frutos foram mantidos a $20^{\circ} \mathrm{C}$, com o auxílio de um colorímetro Minolta CR-400.

As taxas respiratória ( $\mathrm{nmol} \mathrm{de} \mathrm{CO}_{2} \cdot \mathrm{kg}^{-1} \cdot \mathrm{s}^{-1}$ ) e de produção de etileno ( $\mathrm{nmol}$ de $\mathrm{C}_{2} \mathrm{H}_{4} \cdot \mathrm{kg}^{-1} \cdot \mathrm{s}^{-1}$ ) foram quantificadas, colocando-se seis frutos de cada amostra em um recipiente com o volume de $4.100 \mathrm{~mL}$ hermeticamente fechado. As taxas respiratória e de produção de etileno foram obtidas pela diferença

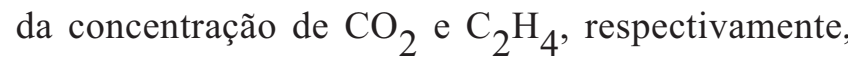
no interior do recipiente, imediatamente após o seu fechamento e depois de 1 hora. A quantificação dos níveis de $\mathrm{CO}_{2}$ e $_{2} \mathrm{H}_{4}$ foi feita em amostras de $1 \mathrm{~mL}$, coletadas da atmosfera interna dos recipientes, com o cromatógrafo a gás, marca Varian ${ }^{\circledR}$, modelo CP-3800, possuindo coluna Porapak $N^{\circledR}$ de $3 \mathrm{~m}$ (240-300mesh), metanador e detector de ionização de chama. As temperaturas da coluna, detector, metanador e injetor foram de $45^{\circ} \mathrm{C}$, $120^{\circ} \mathrm{C}, 300^{\circ} \mathrm{C}$ e $110^{\circ} \mathrm{C}$, respectivamente. Os fluxos de nitrogênio, hidrogênio e ar sintético foram de 70,30 e $300 \mathrm{~mL} \mathrm{~min}^{-1}$, respectivamente.

A firmeza de polpa foi determinada na região equatorial dos frutos, em dois lados opostos, após remoção de uma pequena porção da epiderme e com auxílio de um penetrômetro manual equipado com ponteira de $11 \mathrm{~mm}$ de diâmetro.

Os valores de acidez titulável foram obtidos através de uma amostra de $10 \mathrm{~mL}$ de suco dos frutos, previamente extraído de fatias transversais retiradas da região equatorial das goiabas e trituradas em uma centrífuga elétrica. Esta amostra foi diluída em $100 \mathrm{~mL}$ de água destilada e titulada com solução de hidróxido de sódio $0,1 \mathrm{~N}$ até $\mathrm{pH} 8,1$. Os teores de sólidos solúveis totais foram determinados por refratometria, utilizando-se o suco extraído conforme descrito para a acidez titulável, sendo realizada a correção do efeito da temperatura $\left(20^{\circ} \mathrm{C}\right)$.

A ocorrência de podridões foi avaliada após 30 dias de armazenamento mais três dias de exposição dos frutos a $20^{\circ} \mathrm{C}$. A ocorrência de podridões foi avaliada através da contagem dos frutos afetados, interna e externamente, com lesões maiores do que $5 \mathrm{~mm}$ de diâmetro, causadas por infecção de patógenos. Os resutados foram expressos em porcentagem de frutos podres.
Os dados foram submetidos à análise da variância (ANOVA). Dados em porcentagem foram transformados pela fórmula arco sen $(\mathrm{x} / 100)^{1 / 2}$ antes de serem submetidos à ANOVA. Para a comparação das médias, adotou-se o teste de Tukey $(P<0,05)$.

\section{Resultados e Discussão}

A perda de massa fresca foi maior nos frutos do tratamento com dois dias a $45^{\circ} \mathrm{C}+29$ dias a $2^{\circ} \mathrm{C}$, seguido pelos tratamentos com um dia a $45^{\circ} \mathrm{C}+29$ dias a $2^{\circ} \mathrm{C}$ e com dois dias a $35^{\circ} \mathrm{C}+28$ dias a $2^{\circ} \mathrm{C}$ (Tabela 1). Resultados similares foram obtidos em maçãs 'Fuji' submetidas à imersão em água aquecida, onde se observou aumento da perda de massa com o incremento na temperatura de imersão (Lunardi et al., 2002). Com o aumento da temperatura há maior pressão de vapor de água nos espaços intercelulares, favorecendo a perda de água através da epiderme do fruto (Woods, 1990).

Os frutos armazenados durante todo o período a $2^{\circ} \mathrm{C}$ e aqueles mantidos inicialmente a $45^{\circ} \mathrm{C}$, por um ou dois dias, não apresentaram evolução na coloração da epiderme, mantendo-se verdes (Tabela 2). Goiabas 'Kumagai' armazenadas a $2^{\circ} \mathrm{C}$ também não apresentaram uma evolução normal da cor da epiderme (Jacomino et al., 2000), sendo um sintoma característico de dano pelo frio (Wang, 1994). A inibição do amarelecimento em frutos submetidos ao tratamento inicial a $45^{\circ} \mathrm{C}$ foi acompanhada de baixa produção de etileno, não tendo sido possível detectar produção de etileno durante os dois dias de condicionamento térmico (dados não apresentados). Johnston et al. (2001) constataram que o início do amarelecimento de maçãs coincidiu com o aumento na concentração interna de etileno, sendo que frutos expostos ao etileno apresentaram maior atividade das enzimas clorofilases (Watkins, 2006). Frutos armazenados durante dois dias a $35^{\circ} \mathrm{C}+28$ dias a $2^{\circ} \mathrm{C}$ apresentaram maior amarelecimento da epiderme, seguido de frutos armazenados durante todo o período a $10^{\circ} \mathrm{C}$ (Tabela 2). Em goiabas 'Kumagai' também foi observado o amarelecimento da epiderme durante o armazenamento a $10^{\circ} \mathrm{C}$ (Jacomino et al., 2000). O tratamento com dois dias a $35^{\circ} \mathrm{C}+28$ dias a $2^{\circ} \mathrm{C}$, ao contrário dos tratamentos com condicionamento a $45^{\circ} \mathrm{C}$, 
permitiu que os frutos apresentassem uma evolução na sua cor, mesmo armazenados na temperatura de $2^{\circ} \mathrm{C}$. Cabe ressaltar que somente neste tratamento foi identificada a produção de etileno nos quatro primeiros dias de armazenamento (dados não apresentados). Assim, o resultado obtido por Johnston et al. (2001), citado anteriormente, foram corroborados pelos obtidos neste trabalho.

TABELA 1: Perda de massa fresca (\%) em goiabas 'Pedro Sato' nos quatro primeiros dias de armazenamento. Lages - SC, 2007.

\begin{tabular}{lcccc}
\hline Condição de armazenamento & \multicolumn{5}{c}{ Dias de armazenamento } \\
\hline & $\mathbf{1}^{\mathbf{0}}$ dia & $\mathbf{2}^{\mathbf{0}}$ dia & $\mathbf{3}^{\mathbf{0}}$ dia & $\mathbf{4}^{\mathbf{0}}$ dia \\
\hline 30 dias a $10^{\circ} \mathrm{C}$ & $0,62 \mathrm{~b}$ & $1,17 \mathrm{~cd}$ & $1,70 \mathrm{bc}$ & $2,21 \mathrm{bc}$ \\
30 dias a $2^{\circ} \mathrm{C}$ & $0,39 \mathrm{~b}$ & $0,64 \mathrm{~d}$ & $0,95 \mathrm{c}$ & $1,24 \mathrm{c}$ \\
1 dia a $45^{\circ} \mathrm{C}+29$ dias a $2^{\circ} \mathrm{C}$ & $2,28 \mathrm{a}$ & $2,96 \mathrm{~b}$ & $3,71 \mathrm{~b}$ & $3,39 \mathrm{~b}$ \\
2 dias a $45^{\circ} \mathrm{C}+28$ dias a $2^{\circ} \mathrm{C}$ & $2,80 \mathrm{a}$ & $5,27 \mathrm{a}$ & $6,06 \mathrm{a}$ & $6,32 \mathrm{a}$ \\
2 dias a $35^{\circ} \mathrm{C}+28$ dias a $2^{\circ} \mathrm{C}$ & $1,15 \mathrm{~b}$ & $2,26 \mathrm{bc}$ & $2,86 \mathrm{~b}$ & $3,13 \mathrm{~b}$ \\
C.V. $(\%)$ & 9,52 & 9,28 & 10,67 & 9,73 \\
\hline
\end{tabular}

* Médias nas colunas não seguidas pela mesma letra diferem pelo teste de Tukey $(P<0,05)$.

A taxa respiratória no segundo e terceiro dias de armazenamento foi maior nos frutos do tratamento com dois dias a $45^{\circ} \mathrm{C}+28$ dias a $2^{\circ} \mathrm{C}$, seguido do tratamento com dois dias a $35^{\circ} \mathrm{C}+28$ dias a $2^{\circ} \mathrm{C}$ (Tabela 3 ). Bron et al. (2005) também observaram em goiabas 'Paluma' maior respiração nos frutos mantidos nas temperaturas de $31^{\circ} \mathrm{C}$ e $41^{\circ} \mathrm{C}$, em relação aos frutos armazenados nas temperaturas de $1^{\circ} \mathrm{C}$ e $11^{\circ} \mathrm{C}$, o que pode ser considerado um resultado normal. Porém, estes autores verificaram que os frutos mantidos a $31^{\circ} \mathrm{C}$ apresentaram taxa respiratória maior do que aqueles mantidos a $41^{\circ} \mathrm{C}$, o que, em parte, não está de acordo com os resultados obtidos no presente trabalho. Contudo, em quivi também foi observado que maiores temperaturas causam maior estresse ao fruto, aumentando a taxa respiratória dos mesmos (Antunes e Sfakiotakis, 2000).

No quarto e trigésimo dias de armazenamento, a taxa respiratória foi maior nos frutos armazenados a $10^{\circ} \mathrm{C}$ (Tabela 3). Paull e Chen (2000) afirmam que a exposição a altas temperaturas, inicialmente causa um incremento na taxa respiratória, mas após ocorre um declínio a níveis iguais ou abaixo daqueles observados nos frutos que não ficaram expostos a temperaturas de estresse, estando de acordo com os resultados obtidos no presente trabalho.

TABELA 2: Cor da epiderme $\left(h^{\circ}\right)$ de goiabas 'Pedro Sato' no segundo, terceiro e trigésimo dias de armazenamento refrigerado e durante três dias adicionais de exposição a $20^{\circ} \mathrm{C}$. Lages - SC, 2007.

\begin{tabular}{lcccccc}
\hline $\begin{array}{c}\text { Condição de } \\
\text { armazenamento }\end{array}$ & \multicolumn{3}{c}{$\begin{array}{c}\text { Dias de } \\
\text { armazenamento }\end{array}$} & \multicolumn{3}{c}{ Dias a $\mathbf{2 0} \mathbf{0}^{\circ} \mathrm{C}$} \\
\hline & $\mathbf{2}^{\mathbf{0}}$ & $\mathbf{3}^{\mathbf{0}}$ & $\mathbf{3 0 ^ { \circ }}$ & $\mathbf{1}^{\mathbf{0}}$ & $\mathbf{2}^{\mathbf{0}}$ & $\mathbf{3}^{\mathbf{0}}$ \\
\hline 30 dias a $10^{\circ} \mathrm{C}$ & $111,1 \mathrm{a}$ & $111,8 \mathrm{ab}$ & $102,2 \mathrm{~b}$ & $99,8 \mathrm{~b}$ & $95,7 \mathrm{~b}$ & $93,8 \mathrm{~b}$ \\
30 dias a $2^{\circ} \mathrm{C}$ & $113,1 \mathrm{a}$ & $113,0 \mathrm{a}$ & $110,7 \mathrm{a}$ & $108,1 \mathrm{la}$ & $105,8 \mathrm{a}$ & $103,0 \mathrm{a}$ \\
1 dia a $45^{\circ} \mathrm{C}+29$ dias a $2^{\circ} \mathrm{C}$ & $112,3 \mathrm{a}$ & $112,5 \mathrm{a}$ & $110,3 \mathrm{a}$ & $108,5 \mathrm{a}$ & $106,7 \mathrm{a}$ & $102,5 \mathrm{a}$ \\
2 dias a $45^{\circ} \mathrm{C}+28$ dias a $2^{\circ} \mathrm{C}$ & $109,6 \mathrm{a}$ & $110,6 \mathrm{~b}$ & $107,9 \mathrm{a}$ & $106,5 \mathrm{a}$ & $105,0 \mathrm{a}$ & $102,1 \mathrm{a}$ \\
2 dias a $35^{\circ} \mathrm{C}+28$ dias a $2^{\circ} \mathrm{C}$ & $102,3 \mathrm{~b}$ & $102,4 \mathrm{c}$ & $93,5 \mathrm{c}$ & $93,1 \mathrm{c}$ & $87,4 \mathrm{c}$ & $85,5 \mathrm{c}$ \\
$\mathrm{C} . \mathrm{V} .(\%)$ & 1,32 & 0,52 & 1,15 & 1,40 & 0,82 & 1,25 \\
\hline
\end{tabular}

* Médias nas colunas não seguidas pela mesma letra diferem pelo teste de Tukey $(P<0,05)$.

Observou-se também que os frutos que ficaram expostos inicialmente as temperaturas de $35^{\circ} \mathrm{C}$ e $45^{\circ} \mathrm{C}$ anterior ao armazenamento a $2^{\circ} \mathrm{C}$, apresentaram, após 30 dias, uma taxa respiratória maior do que aqueles frutos que ficaram expostos durante todo o período de armazenamento a $2^{\circ} \mathrm{C}$ (Tabela 3). De acordo com Wang (1982), a primeira resposta ao dano pelo frio inclui mudanças físicas nas membranas celulares de uma estrutura líquido-cristalina para uma estrutura sólido-gel, que tem como conseqüência uma redução da atividade mitocondrial, seguida de desorganização da estrutura celular. Considerando esta afirmação, a manutenção de uma alta taxa respiratória durante o armazenamento a $2^{\circ} \mathrm{C}$, nos frutos que anteriormente foram submetidos a altas temperaturas, pode ser um indicativo de tolerância ao frio, o que pode ser observado no tratamento dois dias a $35^{\circ} \mathrm{C}+28$ dias a $2^{\circ} \mathrm{C}$. No entanto, apesar dos tratamentos com condicionamento térmico a $45^{\circ} \mathrm{C}$ permitirem alta taxa respiratória, os frutos destes tratamentos apresentaram dano pelo frio. Talvez o condicionamento térmico em uma temperatura entre $40^{\circ} \mathrm{C} \mathrm{e} 45^{\circ} \mathrm{C}$, por um tempo menor do que o utilizado no presente trabalho, pode possibilitar o amadurecimento dos frutos e induzir tolerância ao armazenamento em baixas temperaturas.

A firmeza de polpa foi maior nos frutos do tratamento com dois dias a $45^{\circ} \mathrm{C}+28$ dias a $2^{\circ} \mathrm{C}$, 
seguido pelos tratamentos com um dia a $45^{\circ} \mathrm{C}+29$ dias a $2^{\circ} \mathrm{C}$ e dois dias a $35^{\circ} \mathrm{C}+28$ dias a $2^{\circ} \mathrm{C}$ (Tabela 4). Segundo Paull e Chen (2000), a exposição de frutos a temperaturas entre 38 e $40^{\circ} \mathrm{C}$ retardam a redução da firmeza de polpa dos frutos devido a redução de enzimas hidrolíticas de parede celular. Em tomate, foi observado que o condicionamento dos frutos por dois dias a $38^{\circ} \mathrm{C}$ reduziu a produção de RNA mensageiro da enzima poligalacturonase, durante o armazenamento a $2^{\circ} \mathrm{C}$ (Lurie et al., 1996).

TABELA 3: Taxa respiratória (nmol de $\mathrm{CO}_{2} \mathrm{~kg}^{-1} \mathrm{~s}^{-1}$ ) em goiabas 'Pedro Sato' no segundo, terceiro, quarto e trigésimo dias de armazenamento. Lages - SC, 2007.

\begin{tabular}{lcccc}
\hline \multicolumn{1}{c}{$\begin{array}{c}\text { Condição de } \\
\text { armazenamento }\end{array}$} & \multicolumn{4}{c}{ Dias de armazenamento } \\
\hline & $\mathbf{2}^{\mathbf{0}}$ dia & $\mathbf{3}^{\mathbf{0}}$ dia & $\mathbf{4}^{\mathbf{0}}$ dia & $\mathbf{3 0 ^ { \circ }}$ dia \\
\hline 30 dias a $10^{\circ} \mathrm{C}$ & $538,2 \mathrm{c}$ & $284,2 \mathrm{c}$ & $475,8 \mathrm{a}$ & $234,2 \mathrm{a}$ \\
30 dias a $2^{\circ} \mathrm{C}$ & $180,7 \mathrm{~d}$ & $137,1 \mathrm{c}$ & $145,7 \mathrm{~b}$ & $54,0 \mathrm{~d}$ \\
1 dia a $45^{\circ} \mathrm{C}+29$ dias a $2^{\circ} \mathrm{C}$ & $2.287,9 \mathrm{~b}$ & $148,4 \mathrm{c}$ & $144,4 \mathrm{~b}$ & $84,9 \mathrm{c}$ \\
2 dias a $45^{\circ} \mathrm{C}+28$ dias a $2^{\circ} \mathrm{C}$ & $2.796,1 \mathrm{a}$ & $1810,7 \mathrm{a}$ & $274,7 \mathrm{~b}$ & $103,6 \mathrm{bc}$ \\
2 dias a $35^{\circ} \mathrm{C}+28$ dias a $2^{\circ} \mathrm{C}$ & $2.219,5 \mathrm{~b}$ & $1585,8 \mathrm{~b}$ & $164,0 \mathrm{~b}$ & $121,8 \mathrm{~b}$ \\
C.V. $(\%)$ & 8,29 & 8,91 & 22,4 & 8,65 \\
\hline
\end{tabular}

* Médias nas colunas não seguidas pela mesma letra diferem pelo teste de Tukey $(P<0,05)$.

Frutos armazenados durante todo o período de armazenamento a $2^{\circ} \mathrm{C}$ e $10^{\circ} \mathrm{C}$ apresentaram menor acidez titulável e maior teor de sólidos solúveis totais (Tabela 4). Em goiabas 'Kumagai', o armazenamento refrigerado a $2^{\circ} \mathrm{C}$ reduziu os teores de acidez titulável (Jacomino et al., 2000). Estes autores citaram que este resultado, possivelmente, esteja relacionado ao aumento na taxa respiratória dos frutos induzido pela temperatura de $2^{\circ} \mathrm{C}$, por ser uma temperatura que causa danos nos frutos. No entanto, isto não foi observado no presente trabalho. Provavelmente, a baixa temperatura causou um desbalanço na utilização dos substratos respiratórios, ácidos e açúcares, predominando a utilização de ácidos, os quais são prontamente utilizados no ciclo dos ácidos tricarboxílicos. Os maiores teores de sólidos solúveis totais nestes tratamentos podem ser devido à menor utilização dos açúcares pelo processo respiratório, bem como pelo aumento de pectinas solúveis, uma vez que estes frutos apresentaram menor firmeza de polpa.
TABELA 4: Firmeza de polpa, acidez titulável, sólidos solúveis totais (SST) e ocorrência de podridões em goiabas 'Pedro Sato' após 30 dias de armazenamento refrigerado mais três dias de exposição a $20^{\circ} \mathrm{C}$. Lages - SC, 2007.

\begin{tabular}{|c|c|c|c|c|}
\hline $\begin{array}{c}\text { Condição de } \\
\text { armazenamento }\end{array}$ & $\begin{array}{c}\text { Firmeza de } \\
\text { polpa (N) }\end{array}$ & $\begin{array}{l}\text { e Acidez titulável } \\
\left(\text { meq } 100 \mathrm{~mL}^{-1}\right)\end{array}$ & $\begin{array}{c}\text { SST } \\
\left({ }^{\circ} \text { Brix }\right)\end{array}$ & $\begin{array}{c}\text { Podridões } \\
(\%)\end{array}$ \\
\hline 30 dias a $10^{\circ} \mathrm{C}$ & $4,9 \mathrm{c}$ & $5,06 \mathrm{c}$ & $8,40 \mathrm{a}$ & $100,0 \mathrm{a}$ \\
\hline 30 dias a $2^{\circ} \mathrm{C}$ & & & $8,03 a$ & $11,1 b c$ \\
\hline 1 dia a $45^{\circ} \mathrm{C}+$ & 36 & $7,87 \mathrm{ab}$ & 7,77ab & $0,0 \mathrm{c}$ \\
\hline dias a $45^{\circ} \mathrm{C}+28$ dias a $2^{\circ} \mathrm{C}$ & & & 7,87ab & $24,4 b$ \\
\hline dias a $35^{\circ} \mathrm{C}-$ & $30,7 b$ & & $6,97 b$ & $100,0 \mathrm{a}$ \\
\hline C.V. $(\%)$ & 10,7 & 12,0 & 4,56 & 16,31 \\
\hline
\end{tabular}

* Médias nas colunas não seguidas pela mesma letra diferem pelo teste de Tukey $(P<0,05)$.

A ocorrência de podridões foi maior nos frutos armazenados durante 30 dias a $10^{\circ} \mathrm{C}$ e nos frutos mantidos por dois dias a $35^{\circ} \mathrm{C}+28$ dias a $2^{\circ} \mathrm{C}$ (Tabela 4), sendo que as lesões desenvolvidas foram típicas de antracnose, causada por Colletotrichum gloeosporioides. De acordo com Bron et al. (2005), a temperatura de $30^{\circ} \mathrm{C}$ é a temperatura ótima para o desenvolvimento deste fungo. Possivelmente, o tratamento com dois dias a $35^{\circ} \mathrm{C}$ tenha induzido o início da germinação dos esporos, ficando os mesmos quiescentes até o momento em que os frutos foram colocados a temperatura ambiente, após o armazenamento a $2^{\circ} \mathrm{C}$. Já, as temperaturas de $45^{\circ} \mathrm{C}$, durante os primeiros dias de armazenamento, e o armazenamento dos frutos a $2^{\circ} \mathrm{C}$, sem prévio condicionamento a $35^{\circ} \mathrm{C}$, podem ter inviabilizado ou retardado a germinação dos esporos.

Conclui-se que goiabas 'Pedro Sato', armazenadas a $2^{\circ} \mathrm{C}$, sem e com prévio condicionamento térmico durante um ou dois dias a $45^{\circ} \mathrm{C}$, perdem a capacidade de amadurecer. $\mathrm{O}$ condicionamento térmico de dois dias a $35^{\circ} \mathrm{C}$ permite a evolução da coloração da epiderme de goiabas 'Pedro Sato', viabilizando seu armazenamento a $2^{\circ} \mathrm{C}$. O armazenamento durante 30 dias de goiabas 'Pedro Sato' a $10^{\circ} \mathrm{C}$ e o condicionamento térmico de dois dias a $35^{\circ} \mathrm{C}+28$ dias a $2^{\circ} \mathrm{C}$ causam grande perdas por podridões, sendo necessária à utilização de algum tratamento para controle de patógenos. 


\section{Referências}

Antunes, M. D. C.; Sfakiotakis, E. M. 2000. Effect of high temperature stress on ethylene biosynthesis, respiration and ripening of 'Hayward' kiwifruit. Postharvest Biology and Technology, 20: 251-259.

Bron, I. U.; Ribeiro, R. V.; Cavalini, F. C.; Jacomino, A. P.; Trevisan, M. J. 2005. Temperature-related changes in respiration and $\mathrm{Q}_{10}$ coefficient of guava. Scientia Agricola, 62 (5): 458-463.

Chitarra, M. I. F.; Chitarra, A. B. 2005. Pós-colheita de frutas e hortaliças - fisiologia e manuseio. $2^{\mathrm{a}}$ ed. EDUFLA, Lavras, Brasil, 875pp.

Durigan, J. F. 1997. Colheita, conservação e embalagens. Anais do $1^{\circ}$ Simpósio Brasileiro sobre a Cultura da Goiabeira, Jaboticabal, Brasil, p.149-158.

Hardenburg, R. E.; Watada, A. E.; Wang, C. Y. 1986. The commercial storage of fruits, vegetables, and florist, and nursery stocks. USDA, Washington, USA, 130pp.

Jacomino, A. P.; Sarantópoulos, C. I. G. de L.; Sigrist, J. M. M.; Kluge, R. A.; Minami, K. 2000. Armazenamento de goiabas 'Kumagai' sob diferentes temperaturas de refrigeração. Brazilian Journal of Food Technology, 3: 165-169.

Johnston, J. W.; Hewett, E. W.; Hertog, M. L. A. T.; Harker, F. R. 2001. Temperature induces differential softening responses in apple cultivars. Postharvest Biology and Technology, 23: 185-196.

Kluge, R. A.; Azevedo, R. A.; Jomori, M. L. L.; Edagi, F. K.; Jacomino, A. P.; Gaziola, S. A.; Aguila, J. S. 2006. Efeitos de tratamentos térmicos aplicados sobre frutas cítricas armazenadas sob refrigeração. Ciência Rural, 36 (5): 1388-1396.

Lunardi, R.; Seibert, E.; Bender, R. J. 2002. Tolerâcia da maçã ,Fuji` ao tratamento térmico por imersão em água quente. Ciência e Agrotecnologia, 26 (4): 798-803.
Lurie, S.; Handros, A.; Fallif, E.; Shapira, R. 1996. Reversible inhibition of tomato fruit gene expression at high temperature. Plant Physiology, 110: 1207-1214.

Osman, A.; Ayub, W. N. A. 1998. Effects of different postharvest treatments on the respiration patterns of guava (Psidium guajava L.) Acta Horticulturae, 464: 502.

Paull, R. E.; Chen, N. J. 2000. Heat treatment and fruit ripening. Postharvest Biology and Technology, 21: 21-37.

Sabehat, A.; Lurie, S.; Weiss, D. 1998. Expression of small heatshock proteins at low temperature. Plant Phisiology, 117: 651658.

Steffens, C. A.; Brackmann, A.; Pinto, J. A. V.; Eisermann, A. C. 2007. Taxa respiratória de algumas frutas de clima temperado. Pesquisa Agropecuária Brasileira, 42 (3): 313-321.

Wang, C. Y. 1982. Physiological \& Biochemical response of plants to chilling stress. Hortscience, 17: 173-186.

Wang, C. Y. 1994. Chilling injury of tropical horticultural commodities. Hortscience, 29 (9): 986-988.

Watkins, C. B. 2006. The use of 1-methylcyclopropene (1-MCP) on fruits and vegetables. Biotechnology Advances, 24: 389-409.

Woods, J. L. 1990. Moisture loss from fruits and vegetables. Postharvest News and Information, 1 (3): 195-199.

Woolf, A. B.; Bowen, J. H.; Ball, S.; Durand, S.; Laidlaw, W. G.; Ferguson, I. B. 2004. A delay between a $38^{\circ} \mathrm{C}$ pretreatment and damaging high and low temperature treatments influences pretreatment efficacy in ,Hass' avocados. Postharvest Biology and Technology, 34: 143-153. 